\title{
Editorial
}

\section{Vox populi vox dei}

Las encuestas previas al evento electoral del ocho de marzo del 2000 , desarrolladas por instituciones académicas como UTEC, UCA, instituciones y empresas que se dedican a desarrollar estudios estadísticos de opinión pública tuvieron excelentes aciertos al estimar los grandes resultados de los comicios de Diputados y Concejos Municipales.

Se acertó con buen tino al número de abstenciones registradas en el proceso electoral. Se previó la conservación de la mayoría de concejos municipales por parte del partido ARENA, no obstante que se visualizó la disminución del número de Alcaldías en su haber. Se hizo predicción científica del mayor número de diputados que lograría el FMLN.

Los aciertos logrados por los investigadores sociales de la opinión pública fueron posibles gracias a dos elementos fundamentales: 1 . Las técnicas apropiadas de investigación, procesamiento y análisis de la información y, 2. La consulta con los actores esenciales del proceso electoral: los hombres y mujeres salvadoreños/as.

De esos elementos, el más importante es la consulta al soberano, al pueblo salvadoreño, ya que son los ciudadanos y las ciudadanas los que en definitiva deciden asistir al evento electoral, son ellos y ellas quienes optan por participar o no hacerlo. Son ellos los que definen los procesos. Los científicos sociales sólo trabajan técnicamente esa información que la población da gentilmente cuando es consultada.

Algunos políticos partidistas no estuvieron de acuerdo con los resultados de las encuestas de opinión electoral, no obstante su seriedad, veracidad y apego a 
la realidad expresada por el pueblo. $Y$ es que muchos políticos partidistas no están dispuestos a reconocer el sentir y pensar de las mayorías populares que insistentemente les indican los desaciertos de sus políticas económicas, privatizaciones, encarecimientos de la vida, desempleo y desesperanza que producen como consecuencia, las leyes que aprueban y políticas que ejecutan; las cuales sólo favorecen a las minorías socioeconómicas del país.

Reiteradamente el pueblo a través de sus pocos medios, pero legítimos canales de expresión, manifiesta las necesidades de nuevas legislaciones e instituciones que contribuyan a su desarrollo integral como personas humanas que tienen derecho al trabajo, a educación, a alimentación apropiada, en fin a la satisfacción de necesidades individuales, sociales y ambientales. Pero lamentablemente para el pueblo, sus gobernantes, los miembros del Poder Ejecutivo, la mayoría de diputados, ponen oídos sordos a las palabras sabias del pueblo y no le escuchan en su clamor.

En otros países, los gobernantes muestran mayor apertura para estudiar las causas reales de la población. En ese sentido, se incluye como forma de gobierno para los órganos de gobierno legislativo y ejecutivo, la consulta popular, la cual se desarrolla por medio de sondeos de opinión, grupos de enfoque de los problemas sociales.

En algunos casos, la participación ciudadana a título individual o colectivo se integra en las sesiones de discusión de la política fiscal y, más específicamente, en la discusión del gasto público en aquellos rubros que interesa escuchar las prioridades de inversión que reconoce la población.

Estas modalidades de participación y de consulta popular fortalecen la gestión de los gobiernos; permitiendo tender un puente entre la representación y la aproximación a una democracia directa. Pero más que fortalecer unas determinadas formalidades de quehacer político, el binomio: representación-consulta popular mejora la eficiencia en las sociedades actuales, para armonizar el orden social con el progreso social que incluya a todos los sectores sociales y que no excluya a las mayorías populares; más bien que las haga partícipes en construir su propia realidad.

Dentro de la "nueva forma de hacer política" proclamada en El Salvador, no se ha considerado seriamente la forma sabia de consultarle al pueblo sobre los proyectos de ley y las otras decisiones importantes para una buena gestión gubernamental. Se sigúe legislando, diseñando políticas desde el escritorio y la oficina de los órganos de gobierno; se ignoran las necesidades, los relatos y conversaciones del pueblo.

Ya se han hecho algunos ensayos de hacer partícipes a los diferentes sectores sociales como por ejemplo en el "Plan de Nación"; pero este ejercicio participativo no ha tenido una incidencia real y efectiva en la elaboración de políticas de 
gobierno, en leyes y mecanismos que promuevan el desarrollo humano especialmente de los sectores sociales mayoritarios que continúan excluidos del desarroIlo integral.

A propósito de la nueva Asamblea Legislativa y el acuerdo que se recetaron los diputados afiliados a los partidos con posiciones de derecha: ARENA, PCN y PDC, de cambiar la tradición de permitir que el partido con más diputados presida la directiva del órgano legislativo, es algo que violenta los resultados de la consulta electoral hecha al pueblo salvadoreño. Debería pues, seguirse la metodología científica desarrollada con éxito por las instituciones académicas que desarrollan estudios de opinión, de consultar y respetar los designios del pueblo sus consideraciones, de lo contrario se atenta más contra la credibilidad de los procesos electorales y la débil gobernabilidad que nos caracteriza como nación y Estado.

Las consultas informales realizadas por entrevistas, programas participativos de radio y televisión dan cuenta del desacuerdo y malestar que actualmente impera en la opinión pública salvadoreña, debido al "pragmatismo" antiético que han mostrado los diputados de ARENA al aliarse con el PCN y PDC para ganar los puestos de la directiva de la Asamblea Legislativa; todo ello en contraposición de toda una tradición de que el partido con mayor número de diputados es el que asume la presidencia del Organo Legislativo.

Y es que el pueblo salvadoreño no afiliado a partidos políticos y que todavía participa en eventos electorales, frente a este tipo de acciones desarrolladas por los Diputados de la derecha, confirma sus intuiciones de que los políticos son una especie de "adelantados" y oportunistas que sobrepasan el mandato que el pueblo les otorga en cada consulta electoral.

Este tipo de interpretación, a riesgo de ser simple, da fundamento para el desarrollo de actitudes pueden ir de desde la abstención en eventos electorales hasta la radicalización política.

Los resultados y soluciones derivados de las consultas de opinión del pueblo deberían ser admitidos por el pleno de los Diputados de la Asamblea y someterse a su veredicto histórico.

Admitir los resultados del evento elector y ser fiel a una buena tradición de admitir la presidencia en manos del partido político con más diputados electos, requiere de una caballerosidad y condición ética que por ahora está muy alejada de poseer cada uno de los diputados de los partidos de derecha que han concretizado esa alianza que permitió entre ellos la distribución de los puestos de la directiva de la Asamblea Legislativa 